\title{
USO DE EXTRATO FOLIAR DE NIM, Azadirachta indica A. JUSS, PARA O CONTROLE DO PULGÃO Brevicoryne brassicae (L.) EM CULTIVOS DE BRÓCOLIS
}

\author{
Marineide Rosa Vieira ${ }^{1 *}$, Leonardo Saron Peres ${ }^{2}$
}

\begin{abstract}
${ }^{1}$ Profa. Dra. do Departamento de Fitossanidade, Engenharia Rural e Solos, Universidade Estadual Paulista (UNESP), Faculdade de Engenharia, Câmpus de Ilha Solteira, SP. *Email do autor correspondente: marineid@bio.feis.unesp.br

${ }^{2}$ Engenheiro Agrônomo, ex-aluno do curso de Agronomia da Universidade Estadual Paulista (UNESP), Faculdade de Engenharia, Câmpus de Ilha Solteira, SP.
\end{abstract}

RESUMO: O trabalho teve por objetivo avaliar o efeito de diferentes concentrações de extratos aquosos de folhas de nim, Azadirachta indica A. Juss, para o controle do pulgão Brevicoryne brassicae (L.) em uma área de cultivo comercial de brócolis, Brassica oleracea L. var. italica Plenck, no município de Ilha Solteira, São Paulo. O delineamento experimental foi o de blocos ao acaso com quatro tratamentos e quatro repetições. Foram testados extratos aquosos de folhas de nim a $1 \%$ e $2 \%$, além de uma testemunha química, com metomil, e uma testemunha sem pulverização. Três pulverizações foram realizadas no período de $29 / 07$ a 11/08/2014. O extrato de folha a $2 \%$ possibilitou eficiência de 81,5\%, 24 horas após a primeira aplicação, atingindo $93,4 \%$ e $98,5 \%$ após a segunda e a terceira pulverizações, respectivamente. Esse extrato é uma boa opção no controle de $B$. brassicae na cultura do brócolis. Além de não apresentar efeito nocivo ao ambiente e ao consumo dos alimentos, não representa custo adicional para o produtor, uma vez que pode ser produzido a partir de plantas cultivadas na propriedade.

Palavras-chave: Brassicaceae. Brassica oleracea var. italica. Pragas. Controle alternativo.

\section{USE OF NIM, Azadirachta indica A. JUSS, LEAF EXTRACT FOR THE APHID Brevicoryne brassicae (L.) CONTROL ON BROCCOLI CROPS}

\begin{abstract}
The study aimed to evaluate the effect of different concentrations of neem, Azadirachta indica A. Juss, leaves aqueous extracts for the aphid Brevicoryne brassicae (L.) control in an area of commercial cultivation of broccoli, Brassica oleracea L. var. italica Plenck, in the municipality of Ilha Solteira, São Paulo. The statistical design was randomized blocks with four treatments and four replications. Aqueous extracts at $1 \%$ and $2 \%$, a chemical control, methomyl, and a control without spraying were tested. Three sprayings were carried out from $07 / 29$ to $08 / 11 / 2014$. The leaf extract $2 \%$ allowed $81.5 \%$ efficiency 24 hours after the first application, reaching $93.4 \%$ and $98.5 \%$ after the second and third sprayings, respectively. It is a good option to B. brassicae control on broccoli crop. This extract doesn't cause environment and food consumption harmful effect and it can reduce the production cost because can be produced from plants cultivated in the farm.
\end{abstract}

Cultura Agronômica, Ilha Solteira, v.26, n.4, p.492-501, 2017 
Key words: Brassicaceae. Brassica oleracea var. italica. Pests. Alternative control.

\section{INTRODUÇÃO}

A espécie Brassica oleracea L., família Brassicaceae, engloba um grupo de variedades botânicas de grande interesse na alimentação humana. Nesse grupo encontra-se o brócolis (Brassica oleracea L. var. italica Plenck), planta herbácea, folhosa e morfologicamente semelhante à couve-flor, especialmente na fase vegetativa. De acordo com o desenvolvimento da inflorescência nessa variedade, são identificados dois grupos: ramoso e de cabeça. O primeiro caracteriza-se por apresentar grande número de inflorescências pequenas e com botões florais grandes. As colheitas são parceladas e as inflorescências comercializadas em maços. O segundo grupo apresenta uma inflorescência central de interesse comercial, com poucas ramificações laterais. A inflorescência central é de tamanho grande, mais compacta, com botões florais menores do que os do grupo ramoso. O ponto de colheita ocorre quando a cabeça central ou as ramificações laterais apresentamse com botões florais bem desenvolvidos, com coloração verde-escura, porém antes da abertura das flores (FILGUEIRA, 2008).

O cultivo do brócolis é realizado principalmente nos cinturões verdes e a maior parte da produção é destinada ao mercado na forma in natura, nas feiras livres e supermercados. No caso do tipo cabeça, pode ser produzido também para processamento e congelamento (FILGUEIRA, 2008). No estado de São Paulo, a área anual plantada teve acréscimo de 536\%, passando de 482 ha em 1990 (CAMARGO FILHO; MAZZEI, 2000), para aproximadamente $2.584,5$ ha em 2016, com produção de 2,8 milhões engr.dz.mç.15kg (dúzias de maços comercializados em engradados de 15kg) (IEA, 2017).

Durante o seu cultivo, as plantas da família Brassicaceae podem ser atacadas por diversas pragas, entre elas, o pulgão Brevicoryne brassicae (L.), muito frequente em regiões tropicais, ocorrendo em diversas localidades (FILGUEIRA, 2008). Os pulgões dessa espécie apresentam o corpo recoberto por uma camada cerosa branca e formam grandes colônias na face superior das folhas e nas inflorescências. Os danos causados por esse inseto ocorrem devido à sucção contínua de seiva que, consequentemente, produz o engruvinhamento das folhas, prejudicando o desenvolvimento da planta (GALLO et al., 2002). No seu controle são utilizados diversos inseticidas (AGROFIT, 2017).

Uma das maneiras de diminuir a dependência ao uso de agrotóxicos é utilizar métodos alternativos de controle fitossanitário (CAMPANHOLA; BETTIOL, 2003). O controle de pragas utilizando métodos alternativos, incluindo os extratos vegetais, pode ser uma importante estratégia no controle de insetos-praga em pequenas áreas de cultivo, como é o caso das áreas de hortaliças. A utilização de extratos de plantas como inseticidas possui vantagens quando comparada ao uso de inseticidas sintéticos (dependendo da espécie vegetal utilizada), por serem obtidos de recursos renováveis, serem rapidamente degradados

Cultura Agronômica, Ilha Solteira, v.26, n.4, p.492-501, 2017 
no ambiente, apresentarem entre baixa e moderada toxicidade ao homem, pouca fitoxicidade, além de baixo custo (ALTIERI et al., 2003; PENTEADO, 2007).

Uma das espécies mais estudadas para o controle de pragas é a Azadirachta indica A. Juss, conhecida popularmente como nim. O interesse por essa espécie deve-se à presença de um limonóide denominado azadiractina, cuja atividade sobre alguns insetos é comparável à dos melhores inseticidas sintéticos encontrados no mercado (SCHMUTTERER, 1990; MARTINEZ, 2002; NEVES et al., 2003). Os efeitos da azadiractina sobre insetos incluem repelência, deterrência alimentar, interrupção do crescimento, interferência na metamorfose, esterilidade e anormalidades anatômicas (SCHMUTTERER, 1990; MORDUE; NISBET, 2000; MARTINEZ; EMDEN, 2001). Além da azadiractina, os principais componentes biologicamente ativos do nim são meliantriol, limoneno, salanina, nimbim e outros triterpenóides, entre os mais de 150 compostos já isolados para a espécie (SCHMUTTERER, 1990; NEVES et al., 2003).

Produtos derivados do nim podem desempenhar um importante papel no controle de pragas em diferentes culturas, principalmente nos cultivos hortícolas que produzem alimentos para consumo in natura, por serem praticamente não tóxicos ao homem e rapidamente degradados no solo e nas plantas (ISMAN, 2006).

Considerando isto, o objetivo deste trabalho foi avaliar o efeito de extratos vegetais obtidos a partir de folhas de A. indica para o controle da infestação do pulgão $B$. brassicae em cultura comercial de brócolis.

\section{MATERIAL E MÉTODOS}

O experimento foi conduzido em uma pequena área comercial de hortaliças localizada no cinturão verde do município de Ilha Solteira-SP (20²5'58"S e 51²0'33" W; altitude $335 \mathrm{~m})$. A propriedade caracteriza-se pelo cultivo de diversos tipos de hortaliças folhosas, raízes e frutíferas, sendo que as áreas são limitadas por plantas arbustivas e arbóreas servindo de barreira física à dispersão de insetos-pragas e patógenos transportados pelo vento. Toda a produção é destinada para consumo in natura, sendo comercializada em feiras e supermercados no próprio município.

Os extratos testados foram preparados com folhas nim, A. indica, coletadas em uma planta adulta presente na área da Horta dos Aposentados, no cinturão verde de Ilha SolteiraSP. As coletas foram realizadas nos meses de julho e agosto de 2014, de vários pontos da copa, todos com grande incidência luminosa. Para o preparo dos extratos aquosos, as folhas foram coletadas e lavadas com água, sendo descartadas as que apresentavam qualquer sintoma de ataque de pragas ou patógenos s para garantir o uso de folhas saudáveis.

Após a lavagem, as folhas foram colocadas para secar sobre papel toalha e em seguida, foram trituradas em liquidificador com 1 litro de água deionizada durante dois períodos de 15 segundos, com intervalo de três minutos entre eles. Em seguida as suspensões dos extratos permaneceram em repouso em recipiente fechado com filme de

Cultura Agronômica, Ilha Solteira, v.26, n.4, p.492-501, 2017 
PVC esticável por um período de 24 horas, sob temperatura ambiente e sem luminosidade. Após este período, as misturas foram filtradas em uma camada de algodão hidrófilo, por meio de pressão manual para a extração dos filtrados, que foram acondicionados em galões limpos e secos para serem transportados até o campo. No campo, as suspensões preparadas no laboratório foram diluídas para obtenção do volume final de 4 litros.

Quatro tratamentos foram testados e comparados, sendo duas concentrações de extratos aquosos de folhas de A. indica, $1 \%$ e $2 \%$ (concentração peso/volume), uma testemunha química, metomil (Lannate BR) na dose de 0,215g i.a./litro de água e uma testemunha sem pulverização. Em todas as pulverizações foi utilizado o espalhante Aterbane BR na concentração de $0,25 \%$ do volume de calda. As pulverizações foram realizadas em 31/07, 04/08 e 08/08/2014.

O delineamento experimental foi o de blocos casualizados com quatro tratamentos e quatro repetições. Cada parcela foi constituída por seis plantas de brócolis do tipo ramoso cultivadas em espaçamento $0,90 \mathrm{~m}$ entre fileiras e $0,50 \mathrm{~m}$ entre plantas.

Os extratos foram aplicados utilizando-se um pulverizador costal manual, com capacidade para 5 litros, munido de bico tipo cone, com jato dirigido, de modo a molhar completamente toda planta, principalmente inflorescências e a parte abaxial das folhas. Todas as aplicações foram realizadas a partir das 15 horas, visando minimizar a ação dos raios ultravioleta sobre os produtos utilizados.

As populações de pulgões foram avaliadas em quatro datas: 29/07 (avaliação prévia), 01/08, 05/08 e 11/08/2014. Em cada data foram coletadas, de cada planta da parcela, uma folha e uma inflorescência em formação, no local da planta com maior concentração de pulgões. As estruturas destacadas foram individualizadas em sacos de papel e colocadas em caixas de poliestireno. Em laboratório, sob microscópio estereoscópico, foi realizada a contagem do número de pulgões presentes nas folhas e inflorescências.

Os dados de número de pulgões por planta (folha + inflorescência) nas quatro datas de amostragens foram submetidos à análise de variância e as médias comparadas pelo teste de Tukey a 5\% de probabilidade. As análises foram realizadas com o uso do Programa SISVAR (FERREIRA, 2008). Para os cálculos da porcentagem de eficiência (\%E) dos tratamentos testados foi utilizada a fórmula de Abbott (NAKANO et al., 1981):

$\% \mathrm{E}=[(\mathrm{T}-\mathrm{I}) / \mathrm{T}] * 100$, onde, $\mathrm{T}=$ número de insetos vivos na testemunha e $\mathrm{I}=$ número de insetos vivos no tratamento com inseticida.

\section{RESULTADOS E DISCUSSÃO}

$\mathrm{Na}$ área experimental, o pulgão B. brassicae foi detectado em infestação espontânea entre os meses de julho e agosto de 2014. No tratamento controle, sem aplicação de defensivos, a população foi crescente no período do experimento (Figura 1). O aumento populacional coincidiu com o aumento da temperatura e a diminuição da umidade relativa

Cultura Agronômica, Ilha Solteira, v.26, n.4, p.492-501, 2017 
do ar. Houve correlação linear entre os valores das temperaturas médias e dos números médios de pulgões por planta, registrados nas quatro datas de avaliação, para o tratamento controle (Figura 2). O aumento populacional de B. brassicae foi correlacionado com o aumento da temperatura de 21 para $25^{\circ} \mathrm{C}$, temperatura considerada adequada ao desenvolvimento da espécie (CIVIDANES, 2003; JAHAN et al., 2014; MIRMOHAMMADI, 2009). Embora a umidade relativa média do ar tenha diminuído ao longo do período, não foi correlacionada com o número médio de pulgões. No momento do pico populacional, registrado na última avaliação, dia 11/08, a temperatura média foi de 25 ${ }^{\circ} \mathrm{C}$ e a umidade relativa média, $49,7 \%$.

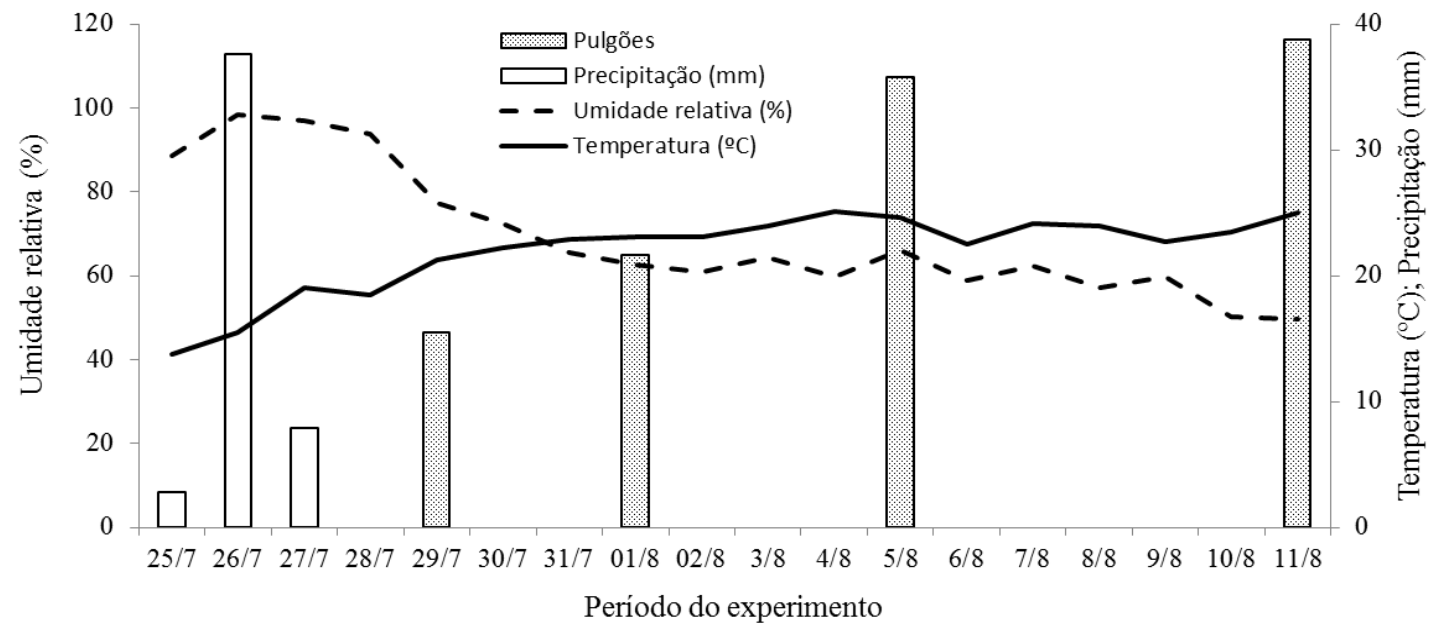

Figura 1. Número médio de pulgões por planta (folha + inflorescência) de Brevicoryne brassicae no tratamento testemunha, nas quatro datas de avaliação, temperatura média diária, umidade relativa média diária e precipitação total diária no período do experimento. Ilha Solteira-SP, 2014.

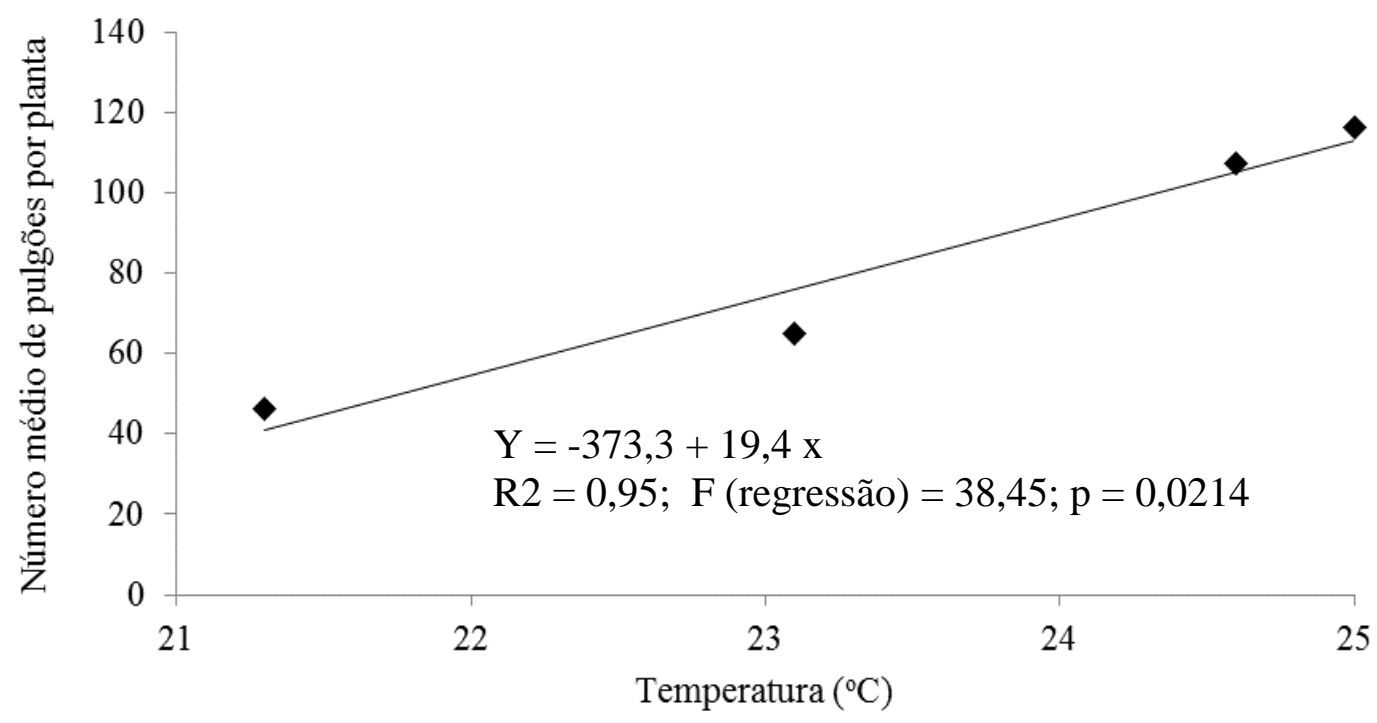

Figura 2. Regressão entre as temperaturas médias e os números médios de pulgões Brevicoryne brassicae registrados no tratamento testemunha, nas quatro datas de avaliação. Ilha Solteira, 2014. 
A partir do dia 28/07 não houve mais a ocorrência de chuvas (Figura 1), o que também pode ter favorecido o aumento populacional de $B$. brassicae, uma vez que a chuva é um dos principais fatores de mortalidade, principalmente de ninfas (FARIAS et al., 2011).

A população de $B$. brassicae estava bem distribuída pela área de cultivo, sem diferença significativa entre os tratamentos na avaliação prévia realizada em 29/07 (Tabela $1)$.

Tabela 1. Número médio de pulgões ${ }^{1}$ de Brevicoryne brassicae por planta (folha + inflorescência), porcentagem de eficiência (E\%) dos tratamentos e datas das pulverizações (P) realizadas com extratos de folhas de Azadirachtina indica e metomil. Ilha Solteira-SP, 2014.

\begin{tabular}{|c|c|c|c|c|c|c|c|}
\hline \multirow{2}{*}{ Tratamentos } & $29 / 07$ & \multirow{2}{*}{$31 / 07$} & $01 / 08$ & \multicolumn{2}{|r|}{$05 / 08$} & \multicolumn{2}{|r|}{$11 / 08$} \\
\hline & Prévia & & $\overline{\text { Pulgões E\% }}$ & & $\overline{\text { Pulgões E\% }}$ & & Pulgões E\% \\
\hline Extrato de fo & $118,8 \mathrm{a}$ & $\mathrm{P}$ & $48,3 \mathrm{ab} 25,1$ & $\mathrm{P}$ & 33,8 ab 68,5 & $P$ & $7,9 \mathrm{~b} \quad 93,2$ \\
\hline Extrato de folhas $2 \%$ & $135,7 \mathrm{a}$ & $\mathrm{P}$ & 12,0 bc 81,5 & $\mathrm{P}$ & 7,1 bc 93,4 & $\mathrm{P}$ & $1,7 \mathrm{~b}$ \\
\hline Testen & $46,3 \mathrm{a}$ & - & $64,9 \mathrm{a}$ & - & $107,3 \mathrm{a}$ & - & $116,2 \mathrm{a}$ \\
\hline $\begin{array}{l}\text { Testemunha química } \\
\text { (metomil) }\end{array}$ & $61,2 \mathrm{a}$ & $\mathrm{P}$ & 6,5 c 90,0 & $\mathrm{P}$ & $1,5 \mathrm{c} \quad 98,6$ & $\mathrm{P}$ & $2,2 \mathrm{~b}$ \\
\hline Teste F & $2,01 \mathrm{~ns}$ & & $11,04 * *$ & & $14,77 * *$ & & $31,46 * *$ \\
\hline $\mathrm{CV}(\%)$ & 14,0 & & 25,5 & & 40,6 & & 37,8 \\
\hline
\end{tabular}

${ }^{1}$ Médias originais. Análise estatística realizada com os dados transformados em log x. Na vertical, médias seguidas pela mesma letra não diferem entre si pelo teste de Tukey a $5 \%$ de probabilidade. ${ }^{*}$ significativo a $1 \%$.

No dia 01/08, 24 horas após a primeira pulverização, os melhores resultados foram obtidos com o metomil e com o extrato aquoso de folhas de nim a $2 \%$, nos quais foram registrados números médios de 6,5 e 12,0 pulgões por planta, respectivamente. A eficiência de controle foi de $81,5 \%$ para o extrato a $2 \%$ e de $90,0 \%$ para a testemunha química. $\mathrm{O}$ número médio de pulgões no tratamento com extrato de folhas a 1\%, 48,3 pulgões por planta, foi semelhante ao registrado na testemunha.

Da mesma forma, na segunda avaliação, realizada em 05/08, após duas aplicações dos tratamentos, os menores números médios de pulgões por planta foram novamente registrados com o metomil e com o extrato aquoso de folha de nim a $2 \%$, com 1,5 e 7,1 pulgões por planta, respectivamente (Tabela 1). A eficiência do extrato foi de $93,4 \%$, muito próximo ao registrado para o metomil, 98,6\%. Não houve diferença significativa entre as populações de $B$. brassicae no tratamento com extrato aquoso de nim a $1 \%$ e na testemunha.

Na última avaliação, de 11/08, após três pulverizações e onze dias após a primeira delas, os três tratamentos inseticidas diferiram da testemunha, com os dois extratos de nim resultando em populações de $B$. brassicae semelhantes à registrada com o metomil (Tabela 1).

Em extratos de folhas de $A$. indica estão presentes diferentes compostos, entre eles, os triterpenos azadiractina, nimbina e salanina, que apresentam efeitos específicos nos insetos, 
como repelência, deterrência alimentar, interrupção do crescimento, interferência na metamorfose, esterilidade e anormalidades anatômicas (SCHMUTTERER, 1990; MORDUE; NISBET, 2000; MARTINEZ; EMDEN, 2001). A literatura registra resultados positivos do uso do nim no controle eficiente de insetos sugadores (CIOCIOLA JÚNIOR; MARTINEZ, 2002; MARTINEZ, 2002, NEVES et al., 2003).

Em laboratório o uso de óleo ou extrato de sementes de nim tem proporcionado altas porcentagens de mortalidades de B. brassicae, como registrado por Carvalho et al. (2008) com o produto comercial Nim-I-Go, que após 48 horas da pulverização resultou em mortalidade de 91,6, 90 e 96,7\%, nas concentrações de 0,75, 1 e 2\% respectivamente. Em casa de vegetação, o óleo das sementes a $1 \%$ proporcionou eficiência de $90 \%$ no controle dessa espécie de pulgão após um período de 14 dias, no qual três aplicações foram feitas (PISSINATI; VENTURA, 2015). Em cultura de repolho, o uso de extrato etanólico de semente de nim a $1 \%$ para controle do pulgão B. brassicae e dos lepidópteros-praga Plutella xylostella (L.) e Hellula undalis (Fabricius) reduziu a infestação do pulgão em 91,3\% e aumentou a produção em 37\% (BAIDOO; ADAM, 2012). Para B. brassicae, Gupta e Suranjana (2015) determinaram o valor de 1,57\% para a CL50 do óleo de semente de nim.

No caso de extrato aquoso de folhas de nim, o efeito inseticida sobre B. brassicae também foi observado em laboratório, por Botti et al. (2015), com mortalidade de 80\%, 72 horas após a pulverização do extrato a 3\%. Da mesma forma, neste estudo, que foi realizado em uma área de produção comercial, o uso de extratos aquosos de folhas foi altamente eficiente no controle dos pulgões, corroborando os dados de laboratório obtidos por aqueles autores e comprovando a possibilidade de uso em campo. Na concentração de $2 \%$ essa eficiência já foi registrada 24 horas após a primeira pulverização, e atingiu, com duas pulverizaçõos espaçadas em quatro dias, 24 horas após a segunda delas, 93,4\%. Com três aplicações, a eficiência nas duas concentrações foi maior que $93 \%$.

O controle de B. brassicae em brócolis, e outras culturas semelhantes, com o uso de extrato de folhas de nim é extremamente interessante tanto pela possibilidade de comercializar um produto sem resíduos tóxicos quanto pela redução dos custos de produção, uma vez que o produtor pode preparar os extratos que serão utilizados a partir de plantas de A. indica mantidas em sua propriedade.

\section{CONCLUSÃO}

Extratos de folha de nim, $A$. indica, a 1 e $2 \%$, são eficientes no controle do pulgão $B$. brassicae em cultura de brócolis.

\section{AGRADECIMENTOS}

Ao Sr. Delcir Sambugari, por ter cedido sua propriedade para a instalação do experimento e pelo apoio durante a sua condução.

Cultura Agronômica, Ilha Solteira, v.26, n.4, p.492-501, 2017 


\section{REFERÊNCIAS BIBLIOGRÁFICAS}

AGROFIT. Sistema de Agrotóxicos Fitossanitários. Ministério da Agricultura, Pecuária e Abastecimento. Disponível em: http://extranet.agricultura.gov.br/agrofit_cons/principal_agrofit_cons. Acesso em: 01 set. 2017.

ALTIERI, M. A.; SILVA, E. N; NICHOLLS, C. I. O papel da diversidade no controle de pragas. São Paulo: Hollos, 2003. 22 p.

BAIDOO, P. K.; ADAM, J. I. The effects of extracts of Lantana camara (L.) and Azadirachta indica (A. Juss) on the population dynamics of Plutella xylostella, Brevicoryne brassicae and Hellula undalis on cabbage. Sustainable Agriculture Research, Toronto, v. 1, n. 2, p.229-234, 2012.

BOTTI, J. M. C.; HOLTZ, A. M.; PAUlO, H. H.; FRANZIN, M. L.; PRATISSOLI, D.; PIRES, A. A. Controle alternativo do Brevicoryne brassicae (Hemiptera: Aphididae) com extratos de diferentes espécies de plantas. Revista Brasileira de Ciências Agrárias, Recife, v. 10, n. 2, p.178-183, 2015.

CAMARGO FILHO, W. P; MAZZEI, A. R. Abastecimento de legumes: tendência de preços. Informações Econômicas, São Paulo, v. 30, n. 10, p.35-49, 2000.

CAMPANHOLA, C.; BETTIOL, W. Métodos alternativos de controle fitossanitário. Jaguariúna: Embrapa Meio Ambiente, 2003. 279 p.

CARVAlho, G. A.; SANTOS, N. M.; PEDrOSO, E. C.; TORRES, A. F. Eficiência do óleo de nim (Azadirachta indica A. Juss) no controle de Brevicoryne brassicae (L.) e Myzus persicae (Sulzer) (Hemiptera: Aphididae) em couve-manteiga Brassica oleracea L. var. acephala. Arquivos do Instituto Biológico, São Paulo, v. 75, n. 2, p.181-186, 2008.

CIVIDANES, F. J. Exigências térmicas de Brevicoryne brassicae e previsão de picos populacionais. Pesquisa Agropecuária Brasileira, Brasília, v. 38, n. 5, p.561-566, 2003.

CIOCIOLA JÚNIOR, A. I.; MARTINEZ, S. S. Nim: alternativa no controle de pragas e doenças. Belo Horizonte: EPAMIG, 2002. 24 p. (Boletim Técnico, 67).

FARIAS E. S.; MORAIS, E. G. F.; PICANÇO, M. C.; MOREIRA, S. S.; CAMPOS, S. O.; BACCI, L. Mortalidade de Brevicoryne brassicae por chuva. Horticultura Brasileira, Vitória da Conquista, v. 29, n. 2, p.S883-S890, 2011. (Suplemento - CD ROM)

FERREIRA, D. F. SISVAR: um programa para análises e ensino de estatística. Revista Científica Symposium, Lavras, v. 6, n. 2, p.36-41, 2008.

FILGUEIRA, F. A. R. Novo manual de olericultura: agrotecnologia moderna na produção e comercialização de hortaliças. 3. ed. Viçosa: UFV, 2008. 421 p.

Cultura Agronômica, Ilha Solteira, v.26, n.4, p.492-501, 2017 
GALLO, D.; NAKANO, O.; WIENDEL, F. M.; SILVEIRA NETO, S.; CARVALHO, R. P. L; BATISTA, G. C.; BERTI FILHO, E.; PARRA, J. R. P.; ZUCCHI, R. A.; ALVES, S. B.; VENDRAMIN, J. D. Entomologia Agrícola. Piracicaba: FEALQ, 2002. 920 p.

GUPTA, M. K.; SURANJANA, P. Effect of oils of patchouli and Neem on Cabbage Aphid, Brevicoryne brassicae (L). Indian Journal of Entomology, New Delhi, v. 77, n. 2, p.105$108,2015$.

ISMAN, M. B. Botanical insecticides, deterrents, and repellents in modern agriculture and an increasingly regulated world. Annual Review of Entomology, Palo Alto, v. 51, p.45-66, 2006.

INSTITUTO DE ECONOMIA AGRÍCOLA - IEA. 2017. Área e produção dos principais produtos da agropecuária do estado de São Paulo. Disponível em: http://www.iea.sp.gov.br/out/bancodedados.html . Acesso em: 04 set. 2017.

JAHAN, F.; ABBASIPOUR, H.; ASKARIANZADEH, A.; HASSANSHAHI, G.; SAEEDIZADEHET, A. Biology and life table parameters of Brevicoryne brassicae (Hemiptera: Aphididae) on cauliflower cultivars. Journal of Insect Science, Cary, v. 14, n. 1, p.1-6, 2014.

MARTINEZ, S. S. O nim Azadirachta indica - natureza, usos múltiplos e produção. Londrina, Instituto Agronômico do Paraná, 2002. 142 p.

MARTINEZ, S. S.; VAN EMDEN, H. F. Growth disruption, abnormalities and mortality of Spodoptera littoralis (Boisduval) (Lepidoptera: Noctuidae) caused by azadirachtin. Neotropical Entomology, Londrina, v. 30, n. 1, p.113-125, 2001.

MIRMOHAMMADI, S.; ALLAHYARI, H.; NEMATOLLAHI, M. R.; ALIREZA SABOORI, A. Effect of host plant on biology and life table parameters of Brevicoryne brassicae (Hemiptera: Aphididae). Annals of the Entomological Society of America, Cary, v. 102, n. 3, p.450-455, 2009.

MORDUE, A. J.; NISBET, A. Azadirachtin from the neem tree Azadirachta indica: its actions against insects. Anais da Sociedade Entomológica do Brasil, Londrina, v. 29, n. 4, p.615-632, 2000.

NAKANO, O.; SILVEIRA NETO, S.; ZUCCHI, R. A. Entomologia econômica. São Paulo: Ceres, 1981. 314 p.

NEVES, B. P.; OLIVEIRA, I. P. NOGUEIRA, J. C. M. Cultivo e utilização do nim indiano. Santo Antônio de Goiás: Embrapa Arroz e Feijão, 2003. 12 p. (Circular Técnica 62)

PENTEADO, S. R. Defensivos alternativos e naturais para uma agricultura saudável. 3. ed. Campinas: Via Orgânica, 2007. 174 p.

PISSINATI, A.; VENTURA, M. U. Control of cabbage aphid Brevicoryne brassicae (L.) using caolin and nem oil. Journal of Entomology, New York, v. 12, n. 1, p.48-54, 2015.

Cultura Agronômica, Ilha Solteira, v.26, n.4, p.492-501, 2017 
SCHMUTTERER, H. Properties and potential of natural pesticides from the neem tree, Azadirachta indica. Annual Review of Entomology, Palo Alto, v. 35, p.271-97, 1990. 